\title{
SISTEM INFORMASI MONITORING PEKERJAAN SALES DI PT. BOSOWA BERLIAN MOTOR CABANG LUWUK BANGGAI BERBASIS WEB
}

\author{
I Ketut Putra Yasa ${ }^{1)}$, Pasilo ${ }^{2)}$ \\ email :poek_gent@yahoo.com ${ }^{l)}$, pasiloselo@gmail.com ${ }^{2)}$
}

\begin{abstract}
Abstraksi
PT. Bosowa Berlian Motor Cabang Luwuk Banggai yang merupakan perusahan dengan label penjualan mobil. Berkembangnya penjualan mobil yang pesat tidak diiringi dengan pembuatan monitoring pekerjaan sales selama ini monitoring pekerjaan sales menggunakan papan tulis yang ditulis setiap satu pekan yang dinilai kurang efektif. Metode penelitian yang digunakan penulis dalam penyusunan karya tulis minor yaitu metode Observasi yaitu Pengumpulan data dengan mengadakan penelitian dan meninjau secara langsung ke lapangan dan metode Studi Pustaka yaitu mengambil referensi dari buku-buku serta sumber-sumber yang dapat dijadikan acuan dalam penulisan penelitian ini. Hasil yang diperoleh pada penelitian yaitu, sistem informasi monitoring pekerjaan sales pada PT. Bosowa Berlian Motor Cabang Luwuk Banggai Selama ini monitoring pekerjaan sales menggunakan papan tulis yang ditulis setiap satu pekan yang dinilai kurang efektif sistem yang ada perlu dikembangkan lagi agar memonitoring pekerja secara up to date. Dengan adanya sistem informasi monitoring pekerjaan sales ini di harapkan dapat membantu proses monitoring Pekerjaan Sales yang lebih efektif dan menarik yang dapat digunakan dengan mudah oleh perusahaan serta dapat memonitoring pekerjaan sales secara up to date.
\end{abstract}

\section{Kata Kunci :}

Sistem Informasi Monitoring Pekerjaan Sales, PT. Bosowa Berlian Motor, Web

\begin{abstract}
PT. Bosowa Berlian Motor Luwuk Banggai Branch which is a company with a car sales label. The rapid development of car sales is not accompanied by the creation of monitoring sales work so far, monitoring sales work using a blackboard written every one week is considered less effective. The research method used by the author in the preparation of minor papers is the observation method, namely collecting data by conducting research and reviewing directly in the field and the library study method, namely taking references from books and sources that can be used as references in writing this research. The results obtained in the research, namely, the information system for monitoring sales work at PT. Bosowa Berlian Motor Luwuk Banggai Branch So far, monitoring sales work using a blackboard written every week is considered ineffective, the existing system needs to be developed again to monitor workers up to date. With this sales job monitoring information system, it is hoped that it can help the Sales Job Monitoring process more effectively and attractively that can be used easily by the company and can monitor sales work up to date
\end{abstract}

Keywords :

Sales Job Monitoring Information System, PT. Bosowa Berlian Motor, Web.

\section{Pendahuluan}

Monitoring penjualan pada PT. Bosowa Berlian Motor Cabang Luwuk Banggai menjadi sebuah kegiatan sehari-sehari yang digunakan kepala cabang untuk monitoring kinerja sales serta pencapaian sales dalam waktu 1-5 hari, pencapaian sales akan diaudit oleh kepala cabang bulan 6 dan bulan 12 memenuhi target atau tidak sesuai planing yang di tulis oleh saleh itu sendiri. Kendala dalam perusahaan tersebut adalah tidak adanya aplikasi untuk memberi informasi pekerjaan sales. Selama ini monitoring pekerjaan sales menggunakan papan tulis yang ditulis setiap satu pekan yang dinilai kurang efektif. Dengan kemudahan fasilitas monitoring sales berbasis website yang bisa diakses dimana saja dan kapan saja, maka akan mempermudah dalam penyampaian informasi baik terhadap sales maupun kepada pimpinan. Batasan masalah penelitian ini adalah sistem informasi ini tidak membahas pembayaran angsuran atau kredit, sistem yang dibuat tidak membahas tentang retur barang dan sistem informasi yang dibuat tidak membahas stok barang. Adapun tujuan dari penelitian ini adalah dapat membuat Sistem Informasi Monitoring Pekerjaan Sales agar mempermudah monitoring penjualan yang lebih efektif dan menarik yang dapat digunakan dengan mudah oleh perusahaan serta dapat memonitoring pekerjaan sales secara up to date. Hasil dari penelitian ini yakni sistem informasi monitoring pekerjaan sales pada PT. Bosowa Berlian Motor Cabang Luwuk Banggai Selama ini monitoring pekerjaan sales menggunakan papan tulis yang ditulis setiap satu pekan yang dinilai kurang efektif sistem yang ada perlu dikembangkan lagi agar memonitoring pekerja secara up to date. Dengan adanya sistem informasi monitoring pekerjaan sales ini di harapkan dapat membantu proses Monitoring Pekerjaan Sales yang lebih efektif 
dan menarik yang dapat digunakan dengan mudah oleh perusahaan serta dapat memonitoring pekerjaan sales secara up to date.

\section{Tinjauan Pustaka}

Sistem informasi merupakan kumpulan dari subsubsistem yang saling berhubungan satu sama lain, dan bekerja sama secara harmonis untuk mencapai satu tujuan, yaitu mengolah data menjadi informasi yang berguna [1]. Monitoring merupakan proses pengumpulan dan analisis informasi berdasarkan indikator yang ditetapkan secara sistematis dan kontinu tentang kegiatan atau program sehingga dapat dilakukan tindakan koreksi untuk penyempurnaan program atau kegiatan itu selanjutnya" [2]. Data Flow Diagram (DFD) merupakan cara atau metode untuk membuat perancangan sebuah sistem yang berorientasi pada alur yang bergerak pada sebuah sistem selanjutnya. Dalam pembuatan sistem informasi DFD sering digunakan. DFD dibuat oleh para analis untuk membuat sebuah sistem yang baik dimana DFD ini nantinya diberikan kepada para programmer untuk melakukan proses coding [3].

\begin{tabular}{|l|c|}
\hline \multicolumn{1}{|c|}{ Nama Simbol } & DeMarco and Yourdan Symbols \\
\hline Entitas eksternal & \\
\hline Proses & \\
\hline Aliran Data & \\
\hline Data Store & \\
\hline
\end{tabular}

Gambar 1. Simbol DFD

Model Entity Relationship digunakan untuk mentransformasikan data-data yang ada di dunia nyata ke dalam bentuk notasi-notasi sebagai perangkat konseptual menjadi diagram data yang dikenal dengan diagram Entity Relationship (diagram E-R) atau dalam istilah lain disebut dengan ERD (Entity Relationship Diagram) [4].

\begin{tabular}{|l|l|l|}
\hline \multicolumn{1}{|c|}{ Nama } & \multicolumn{1}{|c|}{ Simbol } & \multicolumn{1}{|c|}{ Keterangan } \\
\hline Entitas & & $\begin{array}{l}\text { Persegi panjang menyatakan } \\
\text { himpunan entitas adalah orang, } \\
\text { kejadian, atau berada dimana data } \\
\text { akan dikumpulkan. }\end{array}$ \\
\hline Atribut & & $\begin{array}{l}\text { Atribut merupakan informasi yang } \\
\text { diambil tentang sebuah entitas. }\end{array}$ \\
\hline Relasi & & $\begin{array}{l}\text { Belah ketupat menyatakan } \\
\text { himpunan relasi merupakan } \\
\text { hubungan antar entitas. }\end{array}$ \\
\hline Link & & $\begin{array}{l}\text { Garis sebagai penghubung antar } \\
\text { himpunan, relasi, dan himpunan } \\
\text { entitas dengan atributnya. }\end{array}$ \\
\hline
\end{tabular}

Website merupakan sebuah halaman berisi informasi yang dapat di lihat jika komputer anda terkoneksi. Dengan adanya website, semua orang didunia bisa mendapatkan dan mengelola informasi dengan berbagai sumber yang tersedia di internet. Website sendiri saat ini bisa memuat berbagai macam media, mulai dari teks, gambar, suara, serta video [5].

\section{Metode Penelitian}

Metode yang digunakan dalam penelitian ini adalah metode deskriptif dengan pendekatan studi kasus. Metode deskriptif ini bertujuan untuk mendeskripsikan sifat dari apa yang terjadi selama penelitian dan meneliti penyebab dari gejala tertentu. Penelitian deskriptif dengan metode studi kasus dilakukan dengan sangat rinci, mendalam dan teliti. Selanjutnya peneliti yang menggunakan metode studi kasus ini untuk penelitian deskriptif mencoba mencari hubungan antara faktor- faktor yang diteliti. Dalam perancangan dan pengambaran penelitian ini dapat dilihat pada proses sistem yang berjalan dan diusulkan pada PT. Bosowa Berlian Motor Cabang Luwuk Banggai sebagai berikut:

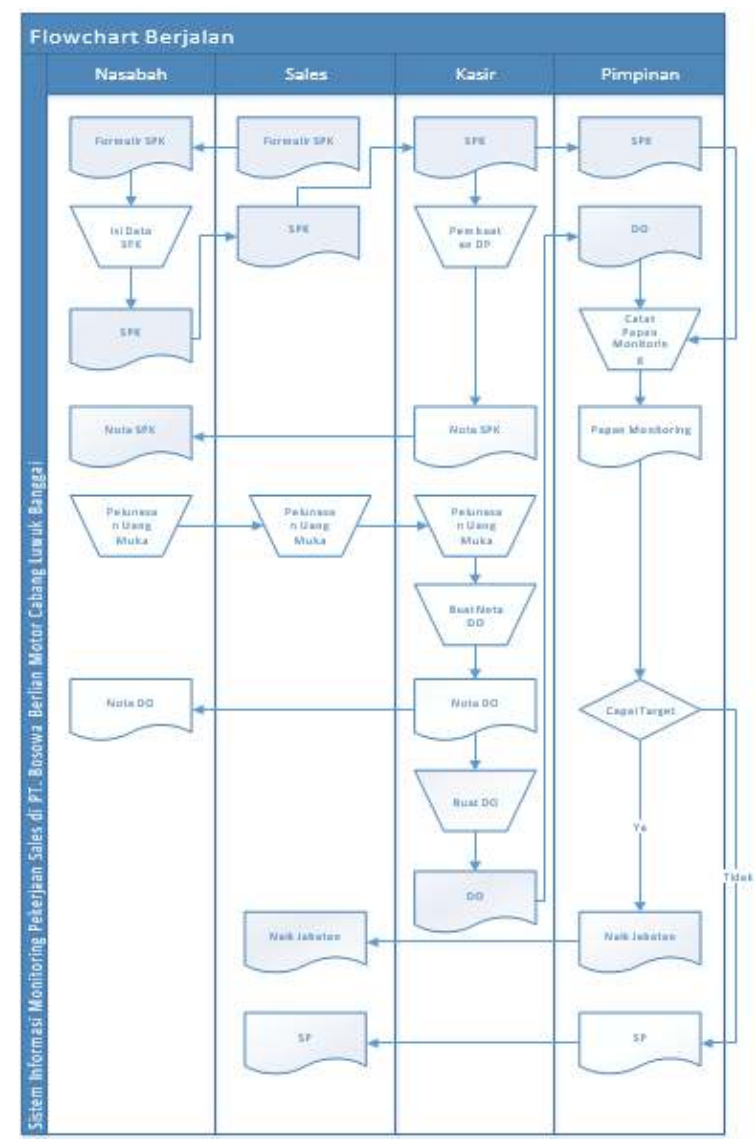

Gambar 3. Sistem yang Sedang Berjalan

Gambar 2. Simbol ERD 


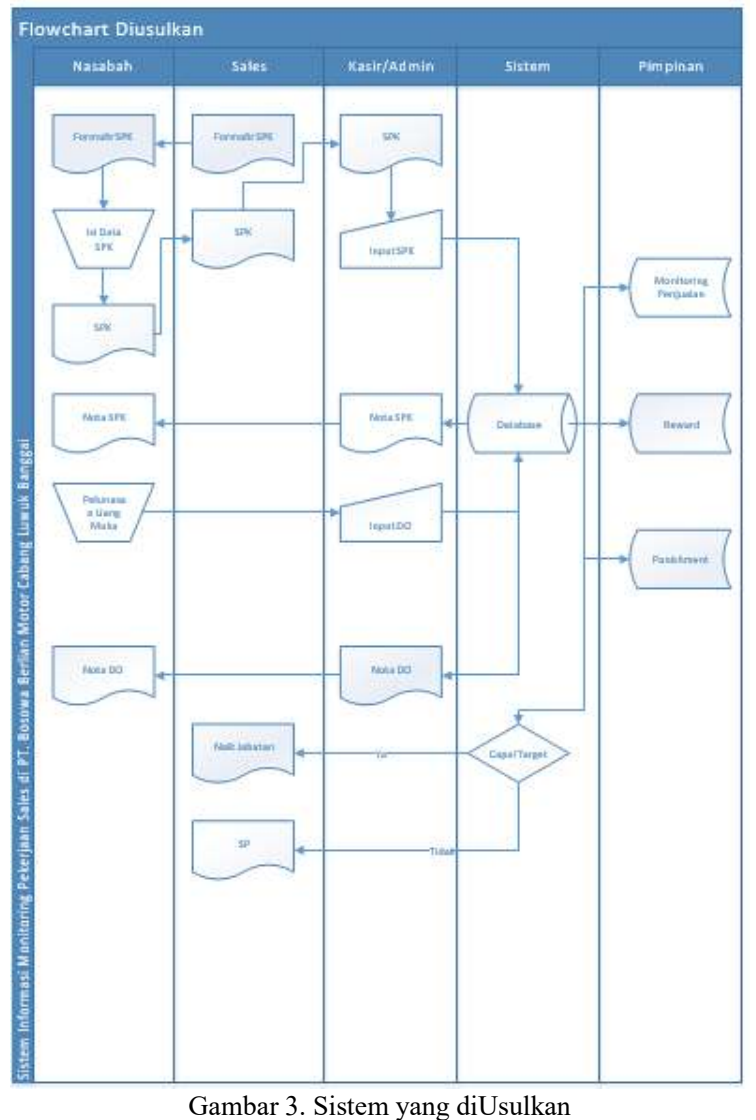

\section{Hasil dan Pembahasan}

Rancangan relasi tabel dalam database yang diperlukan dan akan digunakan dalam Sistem Informasi Monitoring Pekerjaan Sales nantinya adalah sebagai berikut:

\begin{tabular}{|l|l|l|l|l|}
\hline No. & Nama Item & \multicolumn{1}{|c|}{$\begin{array}{c}\text { Data } \\
\text { Type }\end{array}$} & Size & $\begin{array}{c}\text { Field } \\
\text { Kunci }\end{array}$ \\
\hline 1. & Id_sales & int & 11 & $\begin{array}{c}\text { Primary } \\
\text { Key }\end{array}$ \\
\hline 2. & Nama_sales & Varchar & 100 & \\
\hline 3. & Jk & Varchar & 9 & \\
\hline 4. & Tempat_lahir & Varchar & 30 & \\
\hline 5. & Tgl_lahir & date & & \\
\hline 6. & alamat & Varchar & 100 & \\
\hline 7. & Id_golongan & Int & 11 & $\begin{array}{l}\text { Foreign } \\
\text { Key }\end{array}$ \\
\hline 8. & No_hp & Varchar & 12 & \\
\hline 9. & Email & Varchar & 100 & \\
\hline 10. & Password & Varchar & 255 & \\
\hline 11. & Level & Varchar & 8 & \\
\hline
\end{tabular}

Gambar 4. Struktur Tabel Sales

\begin{tabular}{|l|l|l|l|l|}
\hline No. & \multicolumn{1}{|c|}{ Nama Item } & $\begin{array}{c}\text { Data } \\
\text { Type }\end{array}$ & Size & $\begin{array}{c}\text { Field } \\
\text { Kunci }\end{array}$ \\
\hline 1. & Id_nasabah & int & 11 & $\begin{array}{l}\text { Primary } \\
\text { Key }\end{array}$ \\
\hline 2. & Nama_nasabah & Varchar & 150 & \\
\hline 3. & Jenis_kelamin & Varchar & 9 & \\
\hline 4. & status & Varchar & 11 & \\
\hline 5. & alamat & Varchar & 200 & \\
\hline 6. & No_hp & int & 12 & \\
\hline 7. & Id_sales & int & 11 & $\begin{array}{l}\text { Foreign } \\
\text { Key }\end{array}$ \\
\hline
\end{tabular}

Gambar 5. Struktur Tabel Nasabah

\begin{tabular}{|l|l|l|l|l|}
\hline No. & Nama Item & $\begin{array}{l}\text { Data } \\
\text { Type }\end{array}$ & Size & $\begin{array}{l}\text { Field } \\
\text { Kunci }\end{array}$ \\
\hline 1. & Id_spk & int & 11 & $\begin{array}{l}\text { Primary } \\
\text { Key }\end{array}$ \\
\hline 2. & No_spk & varchar & 9 & int \\
\hline 3. & Id_sales & 11 & $\begin{array}{l}\text { Foreign } \\
\text { Key }\end{array}$ \\
\hline 4. & Id_nasabah & int & 11 & $\begin{array}{l}\text { Foreign } \\
\text { Key }\end{array}$ \\
\hline 5. & Id_kendaraan & int & 11 & $\begin{array}{l}\text { Foreign } \\
\text { Key }\end{array}$ \\
\hline 6. & Tgl_spk & date & 50 & \\
\hline 7. & Uang_dp & varchar & 50 & \\
\hline 8. & Status & Int & 11 & \\
\hline 9. & Tgl_do & Date & & \\
\hline 10. & Uang_do & Varchar & 50 & \\
\hline 11. & Total & Varchar & 50 & \\
\hline
\end{tabular}

Gambar 6. Struktur Tabel Surat Pemesanan Kendaraan

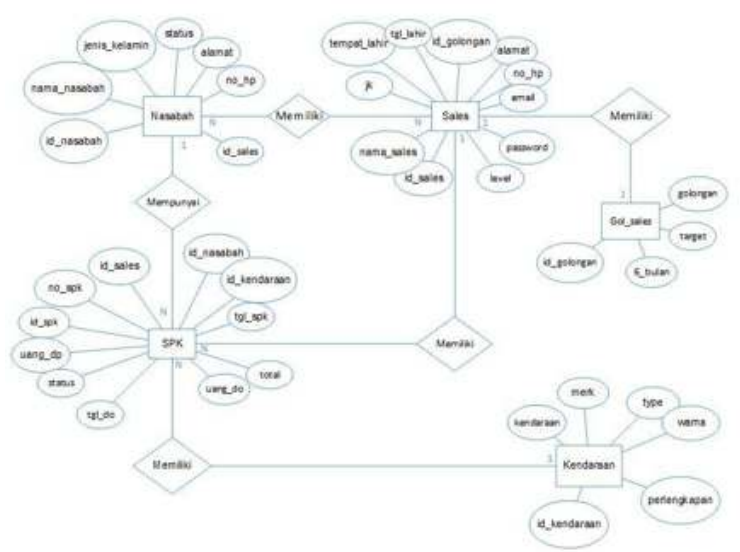

Gambar 7. ERD Sistem

Adapun perancangan sistem dalam penelitian ini adalah sebagai berikut:

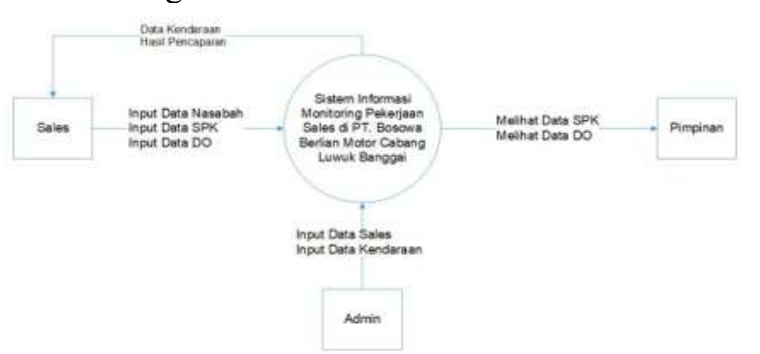

Gambar 8. Diagram Konteks

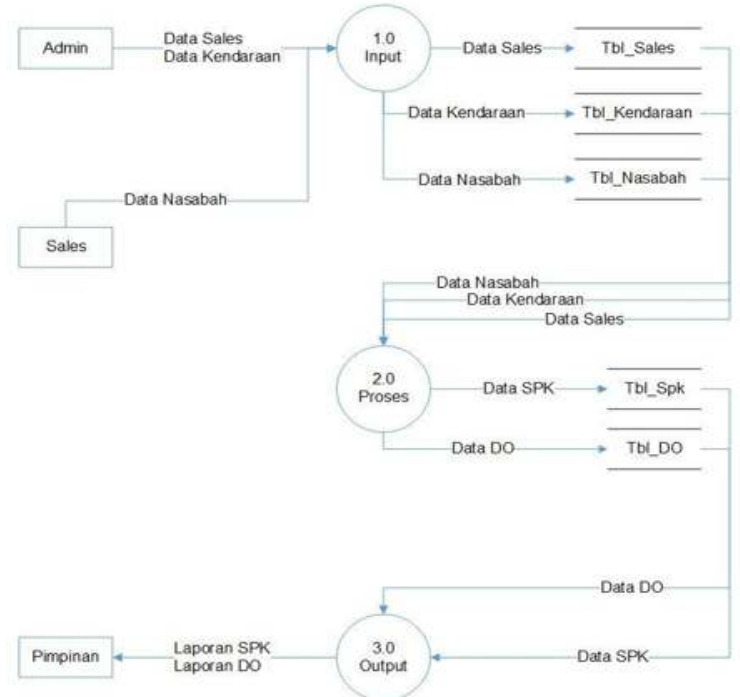

Gambar 9. DFD Level 0 


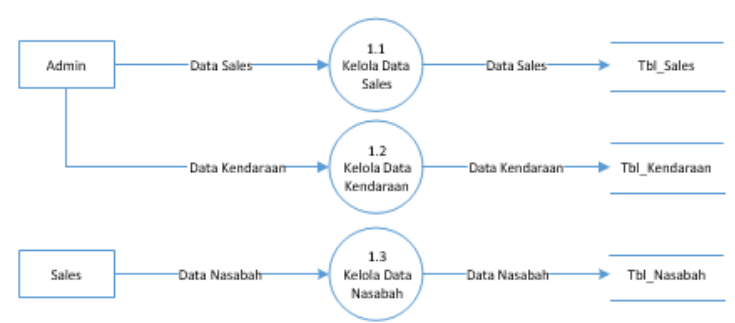

Gambar 10. DFD Level 1

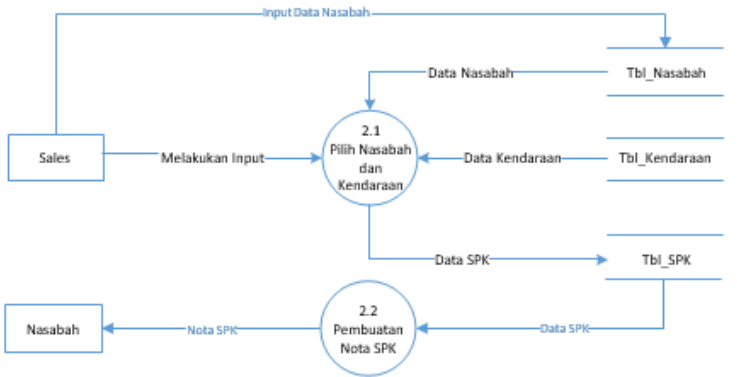

Gambar 11. DFD Level 2 Pembuatan SPK

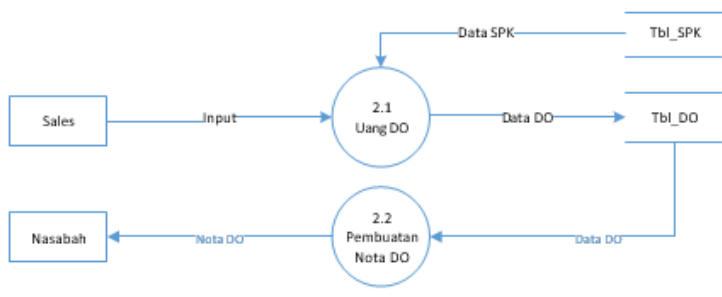

Gambar 12. DFD Level 2 Pembuatan DO

Implementasi merupakan suatu penerapan atau juga sebuah tindakan yang dilakukan dengan berdasarkan suatu rencana yang sudah disusun atau dibuat dengan cermat serta juga terperinci sebelumnya, berikut implementasi sistem:
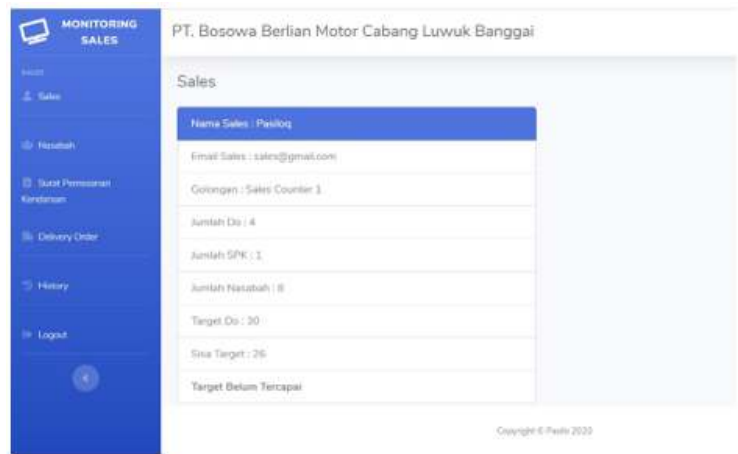

Gambar 13. Form Dashboar Sales

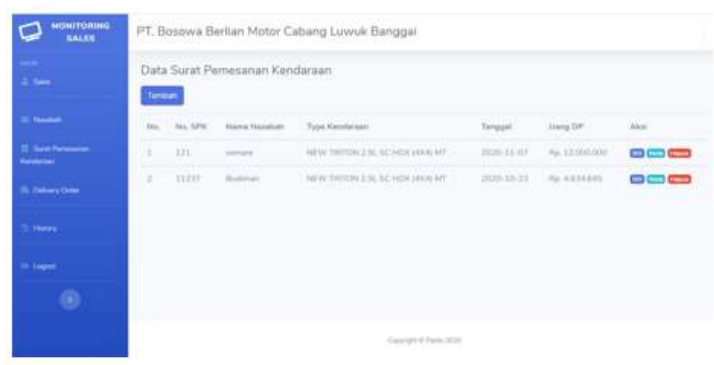

Gambar 14. Form Data Pemesanan Kendaraan

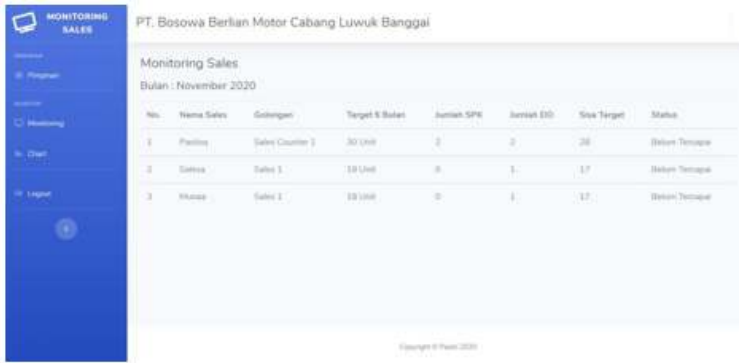

Gambar 15. Form Monitoring Sales

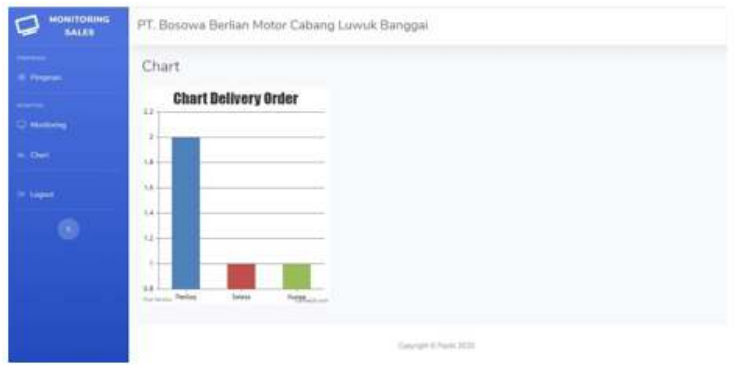

Gambar 16. Form Chart Delivery Order

\section{Kesimpulan dan Saran}

Hasil penelitian mengenai Sistem Informasi Monitoring Pekerjaan Sales di PT. Bosowa Berlian Motor Cabang Luwuk Banggai Berbasis Web, maka dapat disimpulkan bahwa sistem Informasi monitoring pekerjaan sales pada PT. Bosowa Berlian Motor yang telah dirancang ini dapat mempermudah proses monitoring pekerjaan sales yang lebih efisien dan menarik dan sistem Informasi pekerjaan sales ini dapat menghasilkan informasi pencapaian sales namun sistem yang dibuat tidak membahas tentang Angsuran kredit, retur barang dan stok barang. Adapun saran adalah pengguna Sistem Informasi ini harus dapat menguasai dan mengontrol sistem dengan baik, untuk mengurangi tingkat kesalahan pada monitoring pekerjaan sales serta sistem ini perlu dikembangkan lagi agar menjadi sistem informasi yang lebih baik lagi perlu adanya pengembangan tentang sistem angsuran kredit, retur barang dan stok barang.

\section{Daftar Pustaka}

[1] Deni Darmawan dan Kunkun Nur Fauzi. 2016 Sistem Informasi Manajemen. Bandung: PT Remaja Rosdakarya.

[2] Haniah dan Hamidin Dini. 2017. Analisis dan perancangan sistem informasi. Yogyakarta: Deepublish

[3] Nurhachita. 2019. Sistem Informasi Monitoring Honda Sales Order Berbasis Web pada PT. Daya Anugrah Mandiri. Jurnal Intelektualita: Keislaman, Sosial, dan Sains. Vol. 8, No. 1, Juni 2019. ISSN 2303-2952

[4] Deni Darmawan dan Kunkun Nur Fauzi. 2016. Sistem Informasi Manajemen. Bandung: PT Remaja Rosdakarya

[5] Ellya Helmud, Parlia Romadiana dan Dewi Wulan 2019. Pengembangan E-Procurement Menggunakan Model Fast Studi Kasus CV. Mega Sakti di pangkalpinang. Jurnal Informanika, Volume 5 No.2, Juli- Desember 2019. ISSN 2407-1730 